\title{
MÃE E FILHO: OS PRIMEIROS LAÇOS DE APROXIMAÇÃO
}

\author{
Mother and child: the first ties of closeness \\ Madre e hijo: los primeros lazos de aproximación
}

Rosiane da Rosa ${ }^{1}$
Marisa Monticelli $^{4}$

Fernanda Espindola Martins²

Eli Rodrigues Camargo Siebert ${ }^{5}$
Bruna Liceski Gasperi ${ }^{3}$

Nezi Maria Martins ${ }^{6}$

\section{RESUMO}

Estudo qualitativo exploratório-descritivo, realizado no Centro Obstétrico do Hospital Universitário da Universidade Federal de Santa Catarina, de agosto a novembro de 2008, com o objetivo de identificar e analisar os sentimentos maternos expressados pelas mães durante o contato íntimo com os filhos, logo após o parto. Os dados foram coletados pela observação participante e entrevista semiestruturada com 11 mulheres e seus filhos. A análise foi realizada com o suporte da reflexão sobre a Teoria do Apego. Emergiram cinco categorias: a) Sentimentos na hora da expulsão: a espera ansiosa pelo choro do bebê; b) 0 recebimento do filho; c) Sentimentos quanto às respostas do filho à aproximação; d) A primeira separação; e e) Sentimentos sobre 0 acompanhante nas primeiras aproximaç̃̃es com o filho. Conclui-se que os primeiros contatos, na percepção das mulheres, são preponderantes para propiciar o reconhecimento entre mãe e filho, estimulando e incentivando o aprendizado das tarefas culturais da maternagem.

Palavras-chave: Afeto. Relações Mãe-Filho. Parto Humanizado. Recém-nascido. Enfermagem.

\begin{abstract}
The objective of this qualitative, descriptive-exploratory study is to identify and analyze the maternal feelings mothers expressed during intimate contact with their children, immediately upon birth. It was carried out in the Obstetrics Center of the University Hospital at the Federal University of Santa Catarina, Brazil, from August to November of 2008. Data was collected through participant observation and semi-structured interviews, involving eleven women and their children. Analysis was based upon reflective support from the Attachment Theory (Teoria do Apego). Five categories emerged: a) Feelings from the moment of expulsion: the anxious wait for the baby's cry; $b$ ) Receiving the child; c) Feelings as the child's responses to approximation; d) The first separation; and, e) Feelings towards the companion in initial approximations with their child. We conclude that initial contacts, according to women, are preponderant towards promoting recognition between mother and child, stimulating and giving incentive towards learning cultural tasks in maternity.
\end{abstract}

Keywords: Affect. Mother-child relations. Humanized birth. Newborn. Nursing.

\section{Resumen}

Estudio cualitativo exploratorio-descriptivo, realizado en el Centro Obstétrico del Hospital Universitario de la Universidad Federal de Santa Catarina, de agosto a noviembre de 2008, con el objetivo de identificar y analizar los sentimientos de las madres expresados durante el contacto intimo con sus hijos después del parto. Los datos fueron colectados por medio de observación participante y entrevistas semi-estructuradas, con once mujeres y sus hijos. El análisis fue realizado basándose en la Teoría del Apego. Surgieron cinco categorías: a) Sentimientos en el momento de la expulsión del bebé: la espera ansiosa por el llanto del bebé; b) El momento de acoger el recién nacido; c) Sentimientos relacionadas con las respuestas del hijo con la aproximación materna; d) La primera separación; y e) Sentimientos sobre quien acompaña a la madre durante las primeras aproximaciones con el hijo. Se concluyó , que en la percepción de las mujeres, los primeros contactosson preponderantes para propiciar el reconocimiento entre madre e hijo, estimulando e incentivando el aprendizaje de las tareas culturales de la maternidad.

Palabras-clave: Afecto. Relaciones madre-hijo. Parto humanizado. Recién-nacido. Enfermería.

'Aluna do Curso de Especialização em Enfermagem Obstétrica e Neonatal da Universidade do Sul de Santa Catarina (UNISUL). Enfermeira do Programa de Saúde da Família no município de Palhoça/SC. Integrante técnica do Grupo de Pesquisa em Enfermagem na Saúde da Mulher e do Recém-nascido (GRUPESMUR) da Universidade Federal de Santa Catarina (UFSC). Brasil. E-mail: rosiane.nfr@gmail.com, ${ }^{2}$ Aluna do Curso de Especialização em Enfermagem Obstétrica e Neonatal da UNISUL. Enfermeira do Programa Unimed Lar. Integrante técnica do GRUPESMUR. Brasil. E-mail: femartins@gmail.com, ${ }^{3}$ Enfermeira do Programa de Saúde da Família no município de Angelina/SC. Integrante técnica do GRUPESMUR. Brasil. Email: brunagasperi@gmail.com, ${ }^{4}$ Doutora em Enfermagem. Docente do Programa de Pós-Graduação em Enfermagem e do Departamento de Enfermagem da UFSC. Vice-líder do GRUPESMUR. Brasil. E-mail: marisa@nfr.ufsc.br, 5Mestre em Enfermagem. Enfermeira-chefe do Centro Obstétrico da maternidade do Hospital Universitário da UFSC (HU/UFSC). Brasil. E-mail: elircs@gmail.com, ${ }^{6}$ Especialista em Enfermagem Obstétrica. Enfermeira do Centro Obstétrico da maternidade do HU/UFSC. Brasil. E-mail: nezi3608@gmail.com 


\section{INTRODUÇÃO}

Entre os animais mamíferos, o ser humano é o único que separa o recém-nascido de sua mãe. Essa separação pode desencadear malefícios e deixar escapar um momento precioso na vida da mãe e do bebê.

Sob o ponto de vista da criança recém-nascida, sabe-se que ela necessita de contato afetivo contínuo, advindo de uma figura constante-comumente a sua mãe-com a qual estabelecerá relações de apego que venham a assegurar e favorecer seu desenvolvimento biopsicoafetivo. ${ }^{1}$ Ao contrário do que se argumentava até 0 início do século passado, os bebês, quando nascem, não são como tabula rasa, ou seja, destituídos de qualquer experiência sensorial; eles já estão equipados com certo número de sistemas comportamentais, prontos para serem ativados por estímulos, como o contato pele-a-pele (toque), olho-no-olho, a fala e/ou a emanação de sons, o odor (cheiros) e a amamentação. ${ }^{2-3}$

Sob o ponto de vista da mulher que dá à luz, o momento inicial após o parto é considerado precursor do apego, a primeira oportunidade da mãe de ser sensibilizada pelo seu bebê e principiar o exercício social da maternagem. ${ }^{4}$ Para a genitora, este estreitamento serve, por assim dizer, como um arrematamento para o longo percurso gestacional recémfinalizado. ${ }^{2}$

0 Ministério da Saúde brasileiro preconiza que todo recémnascido deva ser colocado junto à mãe para sugar seu leite durante a primeira meia hora de vida, sempre que ambos estiverem em boas condições, o que proporciona o contato necessário para o seguimento do quarto passo a ser implementado nas instituições de saúde para o sucesso do aleitamento materno, conforme indicam as evidências científicas. ${ }^{5-6}$ Essa orientação está de acordo com a Organização Mundial da Saúde, que refere que o contato íntimo entre mãe e filho deva ser iniciado, no máximo, dentro da primeira meia hora após o nascimento, e continuado por pelo menos 30 minutos. ${ }^{6}$

Os profissionais de saúde que atuam nos cenários institucionais onde ocorrem os partos são agentes imprescindíveis no estímulo ao contato precoce, uma vez que atuam diretamente na assistência, podendo ser facilitadores ou complicadores desta prática. ${ }^{7-8}$ Isto vale especialmente para os elementos da equipe de enfermagem, que fundamentam suas atividades no processo de cuidar da mulher, da criança e da família durante o parto e o nascimento. Cremos que, quanto mais compreendermos as percepções e as experiências da puérpera diante desta realidade vivenciada na sala de parto das maternidades, maiores condições teremos de cuidar de modo integral e com valores humanistas, coerentes com os direitos que as familias possuem de serem acolhidas e assistidas nas suas necessidades.

Tal assertiva vale também para o estímulo na formação do apego entre mãe e filho, uma vez que este vínculo é algo aprendido e construído no decorrer dos primeiros anos de vida, sendo um sentimento que é indispensável para a saúde mental de indivíduos adultos. Deste modo, compreender melhor como ocorre esta relação, já nos primeiros minutos de vida do bebê, assim como estimular o contato precoce, são tarefas que devem fazer parte do cotidiano profissional nas salas de parto das instituições de saúde. ${ }^{2-3,9}$ Apesar disso, o contato precoce entre o binômio no momento do nascimento, que é nosso foco de investigação com a presente pesquisa, ainda é um assunto sobre o qual existem lacunas na literatura brasileira, seja sob a perspectiva da enfermagem ou mesmo de outras áreas, como as sociais e humanas. ${ }^{7-8,10-11}$

A preocupação que tivemos com este estudo foi, justamente, a de investigar o vínculo que se estabelece entre a mãe e o filho na sala de parto, sob a perspectiva materna. Acreditamos que, com este modo de proceder, estaremos contribuindo para 0 movimento de humanização do parto e nascimento, já que, como vimos, os estudos têm revelado que a separação mãefilho é potencialmente prejudicial para o estabelecimento do vínculo familiar, seja porque a mulher, sendo privada de iniciar precocemente as manifestações emocionais de afeto que caracterizam o apego, pode, por exemplo, vir a sofrer distúrbios psíquicos de diversos graus no período puerperal ${ }^{2-4}$, seja porque a criança estará exposta a riscos potencialmente prejudiciais ao seu desenvolvimento psicoafetivo. ${ }^{1-4}$

Assim, esta pesquisa teve como objetivo identificar e analisar os sentimentos maternos expressados pelas mães durante 0 contato íntimo com os filhos, logo após o parto.

\section{METODOLOGIA}

Trata-se de uma pesquisa do tipo exploratório-descritiva de natureza qualitativa, realizada no período de agosto a novembro de 2008, no Centro Obstétrico da Maternidade do Hospital Universitário da Universidade Federal de Santa Catarina (HU/UFSC).

Participaram do estudo 11 mulheres que vivenciaram partos vaginais sem distocia e seus recém-nascidos a termo, com índice de vitalidade acima de 7 e que estiveram em contato pele-a-pele com a sua mãe logo após o parto. A idade das mulheres variou entre 17 e 38 anos, sendo uma delas solteira, duas divorciadas e oito casadas. Cinco estavam tendo seu primeiro filho; três mulheres, o segundo; duas, o terceiro; e uma delas, o sétimo filho. Seis mencionaram que a gravidez atual havia sido planejada. 0 número de participantes não foi previamente determinado. A coleta de dados foi interrompida quando os dados começaram a se tornar repetitivos. ${ }^{12}$

A coleta de dados envolveu dois procedimentos. 0 primeiro foi a observação participante, guiado pelo Método 0-P-R (Observação-Participação-Reflexão), ${ }^{12-13}$ que consiste basicamente em iniciar a observação sem participação direta na realidade pesquisada e, aos poucos, ir aumentando 0 gradiente observacional, até atingir o grau de participante total. Tal procedimento foi utilizado com a finalidade de promover/ 
estimular a interação entre mãe e filho ao nascimento. 0 segundo envolveu entrevista semiestruturada? que foi levada a efeito de modo complementar, principalmente para obter os depoimentos das mulheres acerca de seus sentimentos sobre a aproximação com a criança. A observação participante foi adotada nas salas de parto e de recuperação, e a entrevista com as mães foi realizada no Alojamento Conjunto. Após a coleta de dados, as informações foram analisadas em categorias, ${ }^{14}$ utilizando como suporte teórico a Teoria do Apego e a literatura existente sobre par to humanizado.

Os procedimentos analíticos envolveram quatro etapas. Na primeira, denominada apreensão, foi realizada leitura flutuante das informações obtidas por meio das entrevistas e das observações de campo, em que foram destacadas palavraschave, visando responder aos objetivos da pesquisa. Passouse então à etapa de síntese, que envolveu leituras ainda mais aprofundadas ao mapa de dados, a fim de unir informações comuns ou contrastantes, que resultaram no delineamento de alguns códigos que, por sua vez, serviram de base para a formulação das categorias, ou seja, conjuntos de expressões com características parecidas ou que tinham algo em comum, de acordo com os objetivos do estudo. A terceira etapa avançou então para a teorização, em que se buscou interpretar tais categorias, com base no referencial teórico. A última etapa envolveu articulação desses resultados com a literatura, procurando-se convergências e divergências que auxiliassem na superação, ainda que provisória, dos questionamentos da pesquisa.

0 projeto foi enviado ao Comitê de Ética em Pesquisa com Seres Humanos da UFSC, obtendo aprovação sob o parecer $n^{0}$ 135/2008. Para nortear o estudo em relação aos princípios e questões éticas, tivemos por base a Resolução 196/96 do Conselho Nacional de Saúde. A fim de garantir o anonimato das parturientes, foram atribuídos a elas nomes de flores. Esses pseudônimos serão utilizados na apresentação dos resultados e discussão. Todas as participantes do estudo assinaram o Termo de Consentimento Livre e Esclarecido, contendo a solicitação de autorização para a entrevista e para a observação participante, bem como autorização para gravação e fotos, com a finalidade de facilitar os registros.

\section{RESULTADOS E DISCUSSÃO}

0 procedimento analítico deu origem a cinco categorias, que visam identificar os sentimentos das mães durante 0 contato com o filho logo após o parto.

\section{Categoria 1-Sentimentos na hora da expulsão: a espera ansiosa pelo choro do bebê}

0 estudo evidenciou que no exato momento da saída do bebê de dentro da mulher, a preocupação preponderante desta era com relação ao choro. Percebemos que todas as mulheres, sem exceção, permaneciam apreensivas pela chegada de um grito, um gemido, pela chegada de qualquer som que viesse da criança. Trata-se de algo que explicita uma manifestação de vida, uma representação de que a criança, enfim, se faz viva; existe!

Percebemos que esta representação não equivalia a receber informações dos membros da equipe de que a criança estava bem ou que iria ficar bem, mas, sim, de ouvir com os próprios recursos sensoriais o choro da criança. Em alguns momentos observamos que os profissionais referiam que o bebê nascera bem, mas a expressão facial da mulher era de interrogação, até que ouvisse o choro, mesmo que entre a expulsão e a manifestação gutural do bebê não decorresse mais do que alguns segundos.

\begin{abstract}
Às 15h32min nasceu RN masculino. Apresentava certo grau de desconforto e precisou ser aspirado, além de oxigênio inalatório. Durante o tempo em que o RN estava no berço aquecido, Chuva de Prata mostrava-se preocupada, com olhar atento para o berço, e a todo o momento perguntava: "o nenê tá bem, ele tá bem?". Mesmo ouvindo da equipe que o recém-nascido já estaria vindo para perto dela, perguntou mais uma vez se estava bem, pois não o tinha ouvido chorar. (Extratos de Observação - Chuva de Prata)
\end{abstract}

[...] você chorou logo, que bom! (Extratos de Observação - Açucena, falando com o filho)

Notamos ambivalência nestas primeiras manifestações, pois ao mesmo tempo em que as mães consideravam este um momento de intensa alegria, pela finalização do trabalho de parto, também demonstravam tensões, ainda que passageiras, antes de respirarem aliviadas e buscarem saber se a criança era saudável.

Alguns autores clássicos da Teoria do Apego ${ }^{4,15}$ referem que o choro, além de abrir os pulmões, também é uma manifestação de que, provavelmente, a criança sente algumas dores e reações emocionais como o medo e a insegurança diante da nova condição existencial. Em contrapartida, para quem está por perto, o choro é percebido como vivacidade, alegria, sendo aguardado ansiosamente, pois é a prova de que a criança, finalmente, começou a respirar. Esses sentimentos, para os profissionais, respaldam-se na pontuação de Apgar alcançada pelo recém-nascido (como um procedimento técnico que avalia a sua vitalidade), mas, para as mães, as reações de alegria e orgulho ao ouvirem o choro dos bebês parecem estar voltadas quase exclusivamente para a certeza de que a criança "nasceu bem". De qualquer modo, se o bebê não chora imediatamente, causa a todos que assistem ao parto, em especial à mãe, angústia e ansiedade. Se a criança nasce "chocada", sem vida, sem energia, se geme no lugar de gritar, as manifestações maternas de alívio demoram a aparecer. 


\section{Categoria 2 - 0 recebimento do filho}

0 significado desta categoria começava a tomar corpo assim que a mãe se encontrava com a criança real, no exato instante em que recebia o bebê e o tomava como um filho. Percebíamos que aquele instante era marcado por uma importante transição, em que a mãe deixava de perceber aquele novo ser como sendo fantasmático e imaginário ${ }^{2,4}$ ? sentimento característico da simbologia vivenciada durante a gravidez ?, para assumi-lo como um ser concreto. Os dados obtidos com relação a esta categoria mostraram que esta recepção da criança ocorria em três dimensões: conhecendo e se deixando conhecer; aguçando os sistemas sensoriais; e tendo preocupações/cuidados com o recém-nascido.

No que se refere à dimensão Conhecendo e se deixando conhecer, os resultados encontrados revelaram que, quando as mães pegavam seus filhos pela primeira vez, comportamentos de reconhecimento e aproximação começavam a ser instituídos, como se realmente se tratasse de um processo de identificação, agora concreto e sem barreiras físicas. Algo que antes era uma simbiose $^{4}$ passava a ser, vagarosamente, reconhecido como independência: eu sou sua mãe e você é meu filho. Os comportamentos de aproximação demarcam, paradoxalmente, uma separação que será definitiva, já que um terá independência orgânica do outro, sendo, portanto, dois seres humanos distintos, mas simbolicamente ligados. ${ }^{12-13}$

Açucena respirou aliviada e beijou a testa do bebê. Levantou a manta que o cobria, olhou o seu corpinho e falou "é meu". Neste momento trouxe o RN para mais perto de seu corpo, principalmente de seu rosto. Ela o cheirou e o beijou novamente. (Extratos de Observação - Açucena)

Ao receber os filhos no colo, a maioria das mulheres mostrava-se pronta e receptiva para iniciar o contato.

A enfermeira colocou o bebê nos braços da mãe, ainda com o cordão umbilical. Ela estendeu as duas mãos juntas, conservando os cotovelos grudados ao corpo. Ao receber a criança, as mãos continuaram abertas por alguns segundos, como que incrédula pela sensação proporcionada. 0 companheiro de Açucena a abraçava com a mesma reação. (Extratos de Observação - Açucena)

Um aspecto relevante desta etapa de reconhecimento entre mãe e filho refere-se à disposição da mulher para conhecer o bebê, ainda que enfrentando sensações dolorosas, em decorrência do trabalho de parto. Para a maioria das mães, a dor, em si, não era empecilho para o contato, sendo mesmo, para algumas, o próprio ponto de superação das sensações dolorosas.

Ah, é uma satisfação depois de toda aquela dor; depois de acabar, tu vê que valeu a pena, ela tava ali, tava viva, como se fosse um troféu ou uma vitória, recompensa. (Extratos da Entrevista - Brinco de Princesa)

Mas nem todas as mulheres manifestaram a mesma intensidade de sensações com relação à recepção da criança imediatamente após a expulsão:

[...] a mãe olha para todos os cantos da sala, para qualquer movimento que ali ocorre; parece dispersa e não conversa com o bebê. (Extratos de Observação-Gérbera)

Em momentos posteriores, a aproximação com o bebê foi ocorrendo aos poucos, revelando, simplesmente, que aquele não era o melhor momento para a interação com a criança. A manifestação inicial de Gérbera poderia ser decorrente de uma complexidade de outros fatores intervenientes. "Os primeiros sentimentos de amor pelo bebê não são, necessariamente, imediatos no primeiro contato ${ }^{13: 73}$.

No que se refere à dimensão Aguçando os sistemas sensoriais, evidenciou-se que as mulheres, em geral, após receberem seus filhos no colo, aos poucos, iam tocando as áreas com maior sensibilidade tátil do corpo do bebê, como por exemplo, as mãos, a face e os pés. Esta atitude das mães parecia agradar os recém-nascidos, pois estes, sem distinção, ao se sentirem tocados, adotavam posições corporais de conforto. Por outro lado, percebemos que a mãe parecia ter plena consciência da resposta dada por seu bebê, ocorrendo então um ciclo de reações positivas.

O RN começou a chorar, e Camélia, passando a mão no rosto da criança, conversou com ela: "oh bebê, o quê que foi?". Passou a mão no rosto dela, acariciando os lábios e a bochecha. Logo o RN se acalmou. (Extratos de Observação - Camélia)

As mães, sem exceção, procuravam manter seus olhos nos olhos de seus filhos. Parecia que era o momento de se revelar. A intimidade começava e era capaz de gerar sensações que tinham perspectivas de se tornarem progressivamente mais fortes e resistentes à passagem do tempo.

A puérpera não tira os olhos de seu bebê. Está prestando atenção integral a ele. Seu olhar é brilhante e de vez em quando sorri, sem desviar os olhos de seu rosto. (Extratos de Observação - Chuva de Prata)

0 ato de a mãe falar com o bebê também pôde ser observado neste princípio de relação. Todas as mães afirmaram que já conversavam com o filho quando ele ainda estava em seu ventre e asseguraram que a criança já era capaz de reconhecer sua voz e entendê-las: 
[...] eu acho que ela [a recém-nascida] prestava muita atenção ao que eu dizia, na hora que ela nasceu, porque desde a minha barriga eu já conversava com ela e quando eu conversava, mexia. (Extratos da Entrevista - Magnólia)

Outro sistema sensorial que se aguçava nas primeiras aproximações era o olfato. Cheirar era uma das maneiras encontradas pelas mães para iniciar a interação. 0 relato a seguir mostra que, mesmo diante de tantos estímulos ocorrendo quase simultaneamente diante da chegada do bebê, o cheiro não passava despercebido.

Pra mim até o cheiro dele é uma resposta, ele tem o cheirinho dele, não tem outro igual, independente de procedimento. (Extratos da Entrevista-Açucena)

0 contato da mama com o rosto da criança pareceu ser a intenção mais premente, obtendo-se ou não sucesso na amamentação. As mulheres encontravam neste comportamento uma maneira de reencontro com seus filhos. Não simplesmente 0 ato de alimentá-lo, mas sim, uma maneira de ligá-lo ao seu corpo novamente. Compreendemos que a amamentação "em si" não é a ocorrência mais importante neste evento inicial, mas, certamente, o fato de os profissionais da sala de parto atentarem para a interação mãe-bebê poderá resultar em amamentação. Assim, o contato precoce não necessariamente resulta em uma sucção imediata com objetivos nutricionais, mas traz recompensas incontestáveis para a mulher, no sentido de superação de todo o processo parturitivo. ${ }^{16}$

[...] a vontade de amamentar é disso, é de ficar só você e ele. Essa era a vontade de amamentar sim, sentir o cheirinho, ficar perto de mim, fica nove meses carregando ele na barriga e aí todo mundo quer ficar pegando, mas se é pra mamar é só meu. (Extratos da Entrevista - Frésia)

Quanto às Preocupações/cuidados com o recémnascido (RN), ainda na mesa ou cadeira de parto, observamos que a ansiedade mais frequente demonstrada pelas mulheres, após ouvir o choro da criança, era em relação ao aspecto físico desta, mais precisamente em relação à sua coloração.

Açucena acariciou a mão do bebê e perguntou, visivelmente preocupada: "a mão dele está roxinha, não tem problema?" Um dos profissionais da equipe respondeu: "não tem problema, não, é assim mesmo quando nasce. (Extratos de Observação - Açucena)

Esta manifestação materna reforça o pensamento de que a formação do vínculo entre mãe e filho não está somente relacionada a uma afeição, mas também a um processo em que afeição e preocupação tornam a mãe comprometida com 0 recém-nascido, enquanto estiver em seus cuidados. ${ }^{3}$ Esse estado poderia ser considerado como um cuidado que ajudaria a mãe a se adaptar à delicada e sensível necessidade do bebê, conferindo-lhe o status social de responsividade para o exercício da maternagem.

\section{Categoria 3 - Sentimentos maternos quanto às respostas do filho à aproximação}

Entendemos que a interação entre mãe e filho após o nascimento se processa de maneira que a mãe experimente diversas sensações e com elas inicie uma série de estímulos ao bebê. 0 bebê, por sua vez, responde a esses estímulos, dando retorno à mãe. As respostas dos bebês parecem dar o tom para a primeira interação.

Ah, ele ficou bem calminho, respondeu muito bem... quando eu tocava ou então conversava... ele sempre atento; daí continuei fazendo carinho, porque vi que ele tava gostando. Foi muito bom... (Extratos da Entrevista - Dedaleira)

A maioria das mulheres afirmou que o reconhecimento entre mãe e filho se iniciou através da interação advinda durante a gravidez. A "conversa" com os bebês, durante a maturação fetal, familiarizou a criança com a voz da mãe, e, então, após o nascimento, quando aconteceu a interação verbal entre a díade, as mães acreditaram que seus bebês concretizaram 0 reconhecimento:

[...] parecia que ele tava entendendo tudo o que eu tava falando, porque já reconhecia desde a minha barriga. (Extratos da Entrevista - Petúnia)

Percebemos que as mães buscam encontrar respostas em seus filhos, para se sentirem correspondidas, sendo que 0 primeiro período de reatividade provê uma boa oportunidade para a interação precoce.

\section{Categoria 4 - A primeira separação}

Algumas vezes os profissionais da equipe, com a justificativa de realizarem procedimentos imediatos ao recém-nascido, 0 removiam para outro ambiente, separando a díade mãe-filho, justamente no momento em que estas interações que acabamos de descrever estavam sendo concretizadas. Isto nos faz evocar novamente os sentimentos de ansiedade, medo e insegurança que a mulher vivencia por ocasião do parto. Esses sentimentos a deixam mais frágil e suscetível, à ponto de levá-la a cumprir as ordens da equipe que trabalha no centro obstétrico. Ela então aceita sem questionar a rotina que promove a separação com o pequeno bebê. ${ }^{17}$ As notas extraídas do diário de campo confirmam o que a literatura aponta: 
[...] o bebê começou a ficar gemente, e a neonatologista solicitou gentilmente para que a mãe devolvesse o bebê que estava em seu colo, dizendo que a criança precisava ser levada para atendimento. Amãe estendeu os braços, oferecendo a criança, e dizendo: "pode pegar, não tem problema não"; e levou o recém-nascido, sendo acompanhada pelo pai. (Extratos de Observação - Chuva de Prata)

Após ouvir do obstetra que já era suficiente o tempo que o bebê estava no colo da mãe, a mulher entregou o bebê ao membro da equipe que estava mais próximo, dizendo: "agora pode ir pro banho meu amor, vai com elas, vai." (Extratos de Observação Camélia)

Alguns dos procedimentos neonatais são essenciais para a vitalidade do recém-nascido, mas a separação mãe-bebê pode desencadear prejuízo ao início do apego e deixar escapar um momento essencial para o estabelecimento do vínculo. 0 momento íntimo que é desencadeado logo após o parto promove uma adaptação mais suave do bebê ao novo meio e dá continuidade aos laços afetivos que já foram estabelecidos durante a gravidez. Se tais cuidados fossem efetuados ao lado do leito obstétrico, a ruptura afetiva poderia ser bem mais branda e a mulher poderia continuar concentrada em seu bebê, como é o desejo da grande maioria. As expressões verbais e corporais de Açucena são representativas destes sentimentos:

[...] a enfermeira entra na sala e pergunta para a mãe: "o bebê já mamou?"; "ainda não", responde a mãe. Continua a enfermeira: "depois ele volta, agora temos que levá-lo para a sala dos primeiros cuidados. A mãe comenta, sem tirar os olhos da criança: "tá tão gostoso!"Ela cobre o bebê e ele se aconchega. Acaricia sua cabeça, enquanto diz: "por mim ninguém tira ele de mim" (Extratos de Observação - Açucena)

Essa separação, relacionada com a ida do recém-nascido para outro ambiente, a fim de receber cuidados profissionais, deixa a mãe em estado emocional tenso, ainda que ela concorde, sem questionar, já que ali se encontram interesses profissionais que a mãe entende como necessários. Mesmo que ninguém lhe explique quais são estes procedimentos, ela parece estar preparada para "ceder" aos apelos, pois em sua compreensão, se isto não acontecer - e da forma que os profissionais estão requerendo - a criança pode vir a apresentar problemas de saúde. Como nenhuma mãe quer que isso aconteça, sua única conduta é a de concordância. Contudo, nossa percepção acerca da mãe, nos momentos que o bebê não estava presente (mesmo que o acompanhante tivesse ido junto), era de expectativa e ansiedade, e o desejo de saber notícias do filho era similar àquele sentimento presente logo após a expulsão, quando ansiava por ouvir seu choro. Os depoimentos coletados posteriormente, no alojamento conjunto, a respeito desse momento, são bastante significativos:

[...] eu fiquei calma, mas ansiosa. Preocupada eu não tava, porque sabia que, se cuidaram bem de mim, iam cuidar bem do bebê, mas tu fica ansiosa, porque tu quer ver, quer analisar, ver se tá tudo certinho, se deu tudo certo nos exames, daí tu fica ansiosa pra pegar, pra ver, pra conversar, pra falar tá tudo bem, tá tudo certinho com ele, tu quer saber né... preocupada eu não fiquei, realmente eu confio em todo mundo, estava ansiosa mesmo pra ter ele comigo, pra ter certeza. (Extratos da Entrevista Frésia)

Esta questão também é aventada em estudo anterior ${ }^{18}$, em que se constatou que muitas mulheres ficaram preocupadas com seus filhos, ansiosas e com medo da separação, quando os cuidados com o RN eram realizados fora de seu campo visual.

0 adiamento dos cuidados realizados com o RN poderia ser uma solução para evitar a separação entre mãe e filho após o parto. Essa prática também é adotada na maternidade em que realizamos a pesquisa, porém, em nosso entendimento, é necessário ir além. Em vez de remover a criança e o acompanhante, é imperativo que os profissionais e o "ambiente" neonatal sejam trazidos para o "ambiente" da mãe.

\section{Categoria 5 - Sentimentos sobre o acompanhante nas primeiras aproximações com o filho}

0 trabalho de parto é um processo complexo para as mulheres. Geralmente elas ficam tensas e fragilizadas. Essa é uma das justificativas para ter alguém de confiança que possa acompanhá-la nesse período, incentivando-a, auxiliando-a, trazendo segurança, tranquilidade e conforto.

Acho muito importante porque a gente se sente mais confortável, mais calma, ainda mais que era um parto normal. A gente sente mais tranquila, ter uma pessoa ali que você conhece te dando força, é bem importante. (Extratos da Entrevista- Girassol)

Os dados indicaram que, para a maioria das mulheres, 0 acompanhante era a pessoa que realmente fornecia o apoio que elas necessitavam, e acreditavam que eles eram importantes para iniciar o estabelecimento dos primeiros laços com o bebê, promovendo assim a saúde da família, como um dos pré-requisitos para seu desenvolvimento feliz.

Uma assistência de qualidade no parto e a presença de uma pessoa de confiança trazem a possibilidade de maiores benefícios para a mulher e seu bebê, além de ser uma medida 
importante para a humanização do nascimento, o que envolve aproximação e fortalecimento de vínculos entre pai, mãe e filho.

\section{CONSIDERAÇÕES FINAIS}

A proposta de investigar os sentimentos maternos expressados pelas mães durante o contato íntimo com os filhos, logo após o parto, reforçou o pressuposto de que os primeiros momentos que se seguem ao nascimento evidenciam uma fase sensível, precursora de apego, sendo uma oportunidade preciosa para a mãe ser sensibilizada pelo seu bebê.

Percebemos, pelos resultados, que as mães, sem distinção, sentem-se aliviadas ao ouvir o choro do recém-nascido. Mesmo que possa refletir um grito de dor para o bebê, esta manifestação é recebida pelas mães com imensa satisfação, visto que o choro é notado como um indicador de saúde satisfatória da criança.

Evidenciou-se que o recebimento da criança é um momento importante e crucial porque, além de propiciar o reconhecimento entre mãe e filho, estimula os sistemas sensórios do bebê, pois as respostas que o recém-nascido oferece diante dos estímulos que a mãe provoca são de redução ou aumento da atividade motora, aumento do movimento ocular e direcionamento da face ao ouvir a voz materna. As mães, ao verem seus filhos pela primeira vez, sentem vontade de tocá-lo, e os bebês, ao se sentirem acariciados, acalmam-se e começam a perceber com tranquilidade o novo mundo. Os estímulos sensoriais que um provoca no outro faz emergir um ciclo, em que a mulher interage

\section{REFERÊNCIAS}

1. Boing E, Crepaldi MA. Os efeitos do abandono no desenvolvimento psicológico do bebê e a importância do cuidado maternal como fator de proteção. Estud Psicol [on- line]. 2004 dez; [citado 20 ago 2008]; 21(3): [aprox 15 telas]. Disponível em: http://pepsic.bvs-psi.org.br/ $\mathrm{pdf} / \mathrm{epc} / \mathrm{v} 21 \mathrm{n} 3 / \mathrm{v} 21 \mathrm{n} 3 \mathrm{a} 06 . \mathrm{pdf}$

2. Bowlby J. Primórdios do comportamento do apego. In: Bowlby J. Apego e perda: apego. $3^{\mathrm{a}}$ ed. São Paulo (SP): Martins Fontes; 2002. p. 329-69

3. Klaus MH, Kennel JH. Pais/bebê: a formação do apego. Porto Alegre (RS): Artes Médicas Sul; 1993.

4. Winnicott DW. A criança e o seu mundo. $6^{\mathrm{a}}$ ed. Rio de Janeiro (RJ): Zahar; 1982.

5. Manzini FC, Parada CMGL, Juliani CMCM. Aleitamento materno na sala de parto: a visão dos profissionais de saúde. Anais do $8^{\circ}$ Simpósio Brasileiro de Comunicação em Enfermagem 2002 maio. [on-line]São Paulo (SP); [citado 20 ago 2008]. Disponível em: http:// www.proceedings.scielo.br/pdf/sibracen /n8v2/v2a088.pdf

6. Organização Mundial da Saúde-OMS. Evidências científicas dos dez passos para o sucesso no aleitamento materno. Brasília (DF); 2001.

7. Araújo MFM, Schmitz BAS. Iniciativa Hospital Amigo da Criança e incentivo ao aleitamento materno. In: Robledo $\mathrm{H}$, et al. Aleitamento materno no contexto atual: políticas, prática e bases científicas. São Paulo (SP): Sarvier; 2008. p. 135-45. com o bebê e ele corresponde a ela, fazendo com que a mãe se sinta mais segura e continue a estimulá-lo ainda com mais vontade.

Algumas mulheres, durante o contato com o bebê, demonstram certa apreensão com as características apresentadas por ele logo após o nascimento. Fica evidente que, se há uma equipe disposta a esclarecê-las, tal apreensão reverte-se em benefício para o estabelecimento do vínculo.

Uma maneira de deixar as mulheres mais confortáveis e receptíveis nestes primeiros instantes é permitir que elas escolham como acompanhante uma pessoa de confiança que possa apoiá-la e confortá-la, tornando assim a ocasião do nascimento mais harmoniosa e menos traumática.

Compreender os sentimentos maternos com relação ao contato corporal com o bebê, logo após o nascimento, leva-nos a reafirmar que o período que circunda o parto é um momento crucial e esperado pela mulher para ser sensibilizada pelo seu bebê. Se ela se sentir propensa, apoiada e livre para iniciar esta caminhada - desde o dia do parto, no momento em que a criança vem ao mundo, podendo tocá-la, senti-la, acarinhá-la e amamentá-la - terá pistas mais seguras e alvissareiras para começar o aprendizado das "tarefas" culturais da maternagem.

Embora este estudo tenha investigado tão somente os sentimentos das mães nos primeiros contatos com o filho, após o nascimento, certamente outras pesquisas, com outros participantes da sala de parto, como os profissionais e os acompanhantes, poderão aumentar o escopo e a profundidade da compreensão do processo inicial da formação do apego.

8. Cruz DSC, Sumam NS, Spíndola T. Os cuidados imediatos prestados ao recém-nascido e a promoção do vínculo mãe-bebê. Rev Escola Enferm USP [on- line] 2007 dez; [citado 20 ago 2008]; 41(4): [aprox. 8 telas]. Disponível em:

h t t p : / / w w w. s c i e l o . b r / scielophp?scipt=sd_artext\&pid=S008062342007000400021\&ung=pt\&nrm=iso 9. Dias IMAV, Santos RS. Os profissionais de enfermagem diante do nascimento da criança com malformação congênita. Esc Anna Nery Rev Enferm [periódico na internet] 2007 mar; [citado 12 mar 2009]; 11(1): [aprox. 5 telas]. Disponível em: http://www.eean.ufrj.br/ revista_enf/2007_vol11/2007_vol11n01MARÇ0.pdf.

10. Monteiro ICS, Gomes FA, Nakano AMS. Percepção das mulheres acerca do contato precoce e da amamentação em sala de parto. Acta Paul Enferm [on-line] 2006 out/dez; [citado 07 ago 2008]; 19(4): [aprox. 5 telas]. Disponível em http://www.scielo.br/ scielo.php?script=sd_arttextopid=S010321002006000400010ding=pt\&nrm=iso 11. Silva LM, Clapis MJ. Compreendendo a vivência materna no primeiro contato com seu filho na sala de parto. Acta Paul Enferm [periódico na internet]. 2004 jul-set; [citado 07 ago 2008] 17(3): [aprox 5 telas]. Disponível em: http://www.unifesp.br/denf/acta/20 04/17_3/ pdf/art5.pdf

12. Leininger ML. Culture care diversity and universality: a theory of nursing. New York: National League for Nursing Press;1991.

13. Monticelli M. Aproximações culturais entre trabalhadoras de enfermagem e famílias no contexto do nascimento hospitalar: uma 
Mãe e filho: os primeiros laços

Rosa R, Martins FE, Gasperi BL, Monticelli M, Siebert ERC, Martins NM

Esc Anna Nery Rev Enferm 2010 jan-mar; 14 (1): 105-12

etnografia de alojamento conjunto [tese de doutorado]. Florianópolis (SC): Programa de Pós-Graduação em Enfermagem/UFSC; 2003.

14. Trentini M, Paim LMD. Pesquisa em enfermagem: uma modalidade convergente-assistencial. Florianópolis (SC): Ed. UFSC; 1999.

15. Leboyer F. Nascer sorrindo. $14^{a}$ ed. São Paulo (SP): Brasiliense; 2004.

16. Guimarães GP. A formação do apego pais/recém-nascido prétermo e/ou de baixo peso no método mãe-canguru: uma contribuição da enfermagem [dissertação de mestrado]. Florianópolis (SC): Programa de Pós-Graduação em Enfermagem/UFSC; 2006.

17. Nascimento ET, Teruya KM, Bueno LGS. Amamentação na sala de parto. In: Issler $\mathrm{H}$, et al. $\mathrm{O}$ aleitamento materno no contexto atual: políticas, prática e bases científicas. São Paulo (SP): Sarvier; 2008.

18. Cruz DCS, Sumam NS, Spindola T. Os cuidados imediatos prestados ao recém-nascido e a promoção do vínculo mãe-bebê. Rev Esc Enferm USP [on-line] 2007 dez; [citado 23 out 2008]; 41(4): [aprox. 7 telas]. Disponível em: http://www.scielo.br/ scielo.php?script=sa__arttext\&pid=S008062342007000400021\&ling=pt\&nrm=iso 